\title{
Interleukin 5 and granulocyte-macrophage colony-stimulating factor levels in bronchoalveolar lavage fluid in interstitial lung disease
}

\author{
H. Taniguchi*, S. Katoh*, J. Kadota**, Y. Matsubara**, K. Fukushima***, H. Mukae*, \\ S. Matsukura*, S. Kohno**
}

Interleukin 5 and granulocyte-macrophage colony-stimulating factor levels in bronchoalveolar lavage fluid in interstitial lung disease. H. Taniguchi, S. Katoh, J. Kadota, Y. Matsubara, K. Fukushima, H. Mukae, S. Matsukura, S. Kohno. (C)ERS Journals Ltd 2000.

ABSTRACT: The purpose of this study was to evaluate the role of several eosinophil growth factors including interleukin (IL)-5, interleukin (IL)-3 and granulocytemacrophage colony-stimulating factor (GM-CSF) in the pathogenesis of interstitial lung disease with eosinophilia.

IL-5, IL-3 and GM-CSF in bronchoalveolar lavage fluid (BALF) were measured by enzyme-linked immunosorbent assay (ELISA) in patients with eosinophilic pneumonia (EP), bronchiolitis obliterans organizing pneumonia (BOOP), idiopathic pulmonary fibrosis (IPF), sarcoidosis and healthy volunteers.

IL-5 in BALF was high only in patients with EP. IL-3 in BALF was undetectable in the majority of patients with these diseases. GM-CSF in BALF was detectable in 30$67 \%$ of each group of patients. In patients with BOOP and IPF, the number of eosinophils in BALF was higher in patients with detectable GM-CSF than in patients in whom GM-CSF was below the detection limit. Eosinophil cationic protein (ECP) was detected in all patients with EP and some with BOOP and IPF. There was a significant correlation between ECP levels and percentage or number of eosinophils in BALF.

The results suggest the possibility that interleukin 5 in eosinophilic pneumonia, and granulocyte-macrophage colony-stimulating factor in bronchiolitis obliterans organizing pneumonia and idiopathic pulmonary fibrosis may play important roles in eosinophil recruitment in the lung. Activation of eosinophils in the lung is likely to be induced by both interleukin 5 and granulocyte-macrophage colony-stimulating factor. Eur Respir J 2000; 16: 959-964.

\begin{abstract}
*Third Dept of Internal Medicine, Miyazaki Medical College, Miyazaki, **Second Dept of Internal Medicine, Nagasaki University School of Medicine, and ***Nagasaki Prefecture Tarami Hospital, Nagasaki, Japan.
\end{abstract}

Correspondence: S. Katoh

Third Dept of Internal Medicine

Miyazaki Medical College

5200 Kihara, Kiyotake

Miyazaki, 889-1692

Japan

Fax: 81985858305

Keywords: Bronchiolitis obliterans organizing pneumonia eosinophilic pneumonia granulocyte-macrophage colonystimulating factor

idiopathic pulmonary fibrosis interleukin 5

Received: May 151999

Accepted after revision July 202000
Interleukin (IL)-5, interleukin (IL)-3 and granulocytemacrophage colony-stimulating factor (GM-CSF) are eosinophil growth factors as reported by many investigators [1-3]. In addition, IL-5 has also been studied as a growth and differentiation factor for B lymphocytes and eosinophils [4-6] although in humans, it is thought to act mainly on eosinophils. It has been reported that human IL-5 stimulates the function of mature eosinophils and is a potent and selective chemoattractant for eosinophils [4, 7]. Since eosinophils are localized in tissues under a variety of physiological and pathological conditions, locally produced IL-5 may play a role in the selective recruitment of eosinophils from the peripheral circulation. It has been also shown that IL-5 plays an important role in lung eosinophilia in mice by using an anti-IL-5 monoclonal antibody, IL-5-deficient mice and IL-5 receptor $\alpha$ deficient mice [8-10]. The effects of IL-3 and GM-CSF on eosinophils are similar to those of IL-5 [11, 12]. Bronchoalveolar lavage fluid (BALF) of patients with certain interstitial lung diseases (ILDs), such as eosinophilic pneumonia (EP), bronchiolitis obliterans organizing pneumonia (BOOP), and idiopathic pulmonary fibrosis (IPF) [13-15], contains a high number of eosinophils and elevated levels of IL-5 and GM-CSF [16]. In addition, IL-3 is a growth and survival factor for multipotent haematopoietic stem cells and activates not only eosinophils but also macrophages and natural killer (NK) cells [2]. On the other hand, GM-CSF stimulates the generation of leukocyte precursors, such as monocytes, neutrophils and eosinophils, and activates antigen presenting cells [1].

Eosinophil cationic protein (ECP) are also elevated in the bronchoalveolar lavage fluid of patients with ILD such as IPF and EP and there is a significant relationship between the number of eosinophils and ECP levels in BALF of such patients $[13,14]$. Although the exact aetiology of these diseases is unknown, accumulation of eosinophils in the lung is thought to be one component of the pathogenesis of these disorders since ECP is a cytotoxic substance and the presence of high concentrations of ECP in BALF of patients with IPF and EP indicates activation of eosinophils in the lung [17].

In this study, the concentrations of IL-5, IL-3 and GMCSF in BALF of patients with ILD and healthy subjects 
was measured to evaluate the role of these cytokines in eosinophil recruitment into the lung in eosinophilic lung disease. The relationship between each cytokine and eosinophils recovered from BALF was investigated, and the ECP concentrations in BALF in these diseases as a marker of degranulation of activated eosinophils was measured.

\section{Materials and methods}

\section{Patient population}

Included in this study were nine untreated patients with EP ( 6 females and 3 males, aged $42.8 \pm 16.8 \mathrm{yrs}$ ), 16 with BOOP (11 females and 5 males, aged 63.311.3 yrs), 14 with IPF ( 3 females and 11 males, aged $63.1 \pm 6.3$ yrs) and 17 with sarcoidosis (13 females and 4 males, aged 45.7 $\pm 5.1 \mathrm{yrs}$ ), who were referred to the Miyazaki Medical College Hospital (Miyazaki, Japan) and Nagasaki University hospital, as well as 14 healthy adult volunteers (3 females and 11 males, aged $24.8 \pm 4.2$ yrs). None of the patients with ILDs in this study were treated with corticosteroids. At the time of the investigation, one patient with EP, three with BOOP, six with IPF, four with sarcoidosis and no volunteers were smokers.

The diagnosis of EP was based on clinical criteria; patients with no known cause of EP (drugs, parasitic infection and fungal disease), with acute or chronic dyspnoea, interstitial infiltrates on chest radiographs, pulmonary eosinophilia, and prompt resolution of clinical and radiographic abnormalities with or without corticosteroid therapy. All patients showed peripheral eosinophilia. The diagnosis of BOOP was based on clinicopathologic evaluation as following: 1) consistent clinical history and radiographic findings (chest roentgenograms showed alveolar, interstitial or mixed opacities), as described [18]; 2) typical histologic pattern of BOOP at transbronchial biopsy (in three patients by open lung biopsy); 3) no evidence of any underlying disorder or known aetiology of BOOP, and blood eosinophilia; 4) rapid response to corticosteroid treatment.

The diagnosis of IPF was based on the following criteria: 1) no clinical history of exposure to environmental agents known to cause interstitial lung disease; 2) no history of chronic lung infections; 3 ) evidence of interstitial infiltrates on chest roentgenogram and chest CT scan; 4) pulmonary function test with restrictive ventilatory defect; and 5) histological evidence of interstitial pneumonitis with varying degrees of interstitial fibrosis without granulomas. The diagnosis of sarcoidosis was made by examination of biopsy specimens obtained from lungs, lymph nodes, or skin showing noncaseating epithelioid cell granulomas, with no evidence of inorganic material known to cause granulomatous diseases.

\section{Bronchoalveolar lavage}

After obtaining informed written consent from the subject, BAL was performed using a flexible fibreoptic bronchoscope (Olympus BF P-20; Olympus, Tokyo, Japan) under local anaesthesia of the upper airway with $2 \%$ lidocaine as described previously [19]. The broncho- scope was wedged into the subsegmental bronchus of the right middle lobe or, in patients with EP and BOOP, into areas of lung parenchyma otherwise normal on chest roentgenogram, and 150 or $200 \mathrm{~mL}$ normal saline was instilled in $50 \mathrm{~mL}$ aliquots. BAL fluid was filtered through sterile nylon mesh and centrifuged at $160 \times \mathrm{g}$ for 2 min to obtain the cell preparation. The cells were later stained by the May-Giemsa method and a differential count was performed on 200 cells. The remaining fluid was centrifuged at $500 \times \mathrm{g}$ for $5 \mathrm{~min}$ and the supernatant stored at $-80^{\circ} \mathrm{C}$ until use.

Measurement of interleukin 5 and 3, granulocytemacrophage colony-stimulating factor and eosinophil cationic protein in bronchoalveolar lavage fluid

IL-5 was measured using an enzyme-linked immunosorbent assay (ELISA). Briefly, $50 \mu \mathrm{L}$ monoclonal antibody to human IL-5 (TRFK5; Pharmingen, San Diego, CA, USA) $\left(4 \mu \mathrm{g} \cdot \mathrm{mL}^{-1}\right)$ was bound to microtitre plates by incubating at $4^{\circ} \mathrm{C}$ overnight. The wells were washed twice with phosphate-buffered saline (PBS) containing $0.05 \%$ Tween 20. After blocking with $400 \mu \mathrm{L}$ PBS $/ 10 \%$ foetal calf serum for $2 \mathrm{~h}, 100 \mu \mathrm{L}$ BAL supernatant and recombinant human IL-5 (Pharmingen) were added to each well and incubated at $4{ }^{\circ} \mathrm{C}$ overnight. After washing twice with $0.05 \%$ Tween/PBS, $100 \mu \mathrm{L}$ secondary antibody (biotinylated antihuman IL-5 monoclonal antibody (JES1-SA10; Pharmingen)) (4 $\left.\mu \mathrm{g} \cdot \mathrm{mL}^{-1}\right)$ was added to each well and incubated at room temperature for $1 \mathrm{~h}$, followed by further $1 \mathrm{~h}$ incubation with $100 \mu \mathrm{L}$ of peroxidase conjugated streptavidin. Wells were subsequently washed 5 times with $0.05 \%$ Tween/PBS and incubated with $0.11 \mathrm{M}$ sodium acetate buffer ( $\mathrm{pH} 5.5$ ) containing tetramethylbenzidine for 15 min or until a suitable colour developed. The reaction was stopped by adding $100 \mu \mathrm{L} 1.8 \mathrm{M} \mathrm{H}_{2} \mathrm{SO}_{4}$ to each well. Absorbance of the plates was read at $450 \mathrm{~nm}$ in an ELISA reader. The assay was linear over the range of approximately $20-680 \mathrm{pg} \cdot \mathrm{mL}^{-1}$ and was specific for IL-5 without cross-reactivity to recombinant IL-3 or GM-CSF. The average level from duplicate assays was obtained. IL-3 and GM-CSF were measured using an ELISA kit (R\&D systems, Minneapolis, USA). The detection limits were 20.0, 31.2, $3.9 \mathrm{pg} \cdot \mathrm{mL}^{-1}$ for IL-5, IL-3 and GM-CSF, respectively. ECP was measured using an ECP radioimmunoassay (RIA) kit (Pharmacia Diagnostics, Uppsala, Sweden). The detection limit of ECP was $2 \mu \mathrm{g} \cdot \mathrm{L}^{-1}$. Concentrations below the lower limit of detection were assumed to be zero for the purpose of statistical analysis. The absolute values of cytokines were reported in this study, because the level of the cytokines was not influenced by the concentration of albumin in a previous study carried out by the authors [20].

\section{Statistical analysis}

All data are expressed as mean \pm standard deviation (SD). Statistical comparisons were performed by the MannWhitney U-test to examine differences between the means of unpaired samples. The Spearman's rank correlation was used to examine the relationship between parameters. Significance was defined as $\mathrm{p}<0.05$. 


\section{Results}

\section{Characteristics of bronchoalveolar lavage fluid cells}

The total number and differential count of leukocytes in BALF are summarized in table 1. The total number of cells $\cdot \mathrm{mL}^{-1}$ of BALF in all patient groups was higher than that in healthy subjects. In the differential cell count, the percentage/absolute number of eosinophils in EP $(\mathrm{p}<0.01 / \mathrm{p}<0.01)$ and IPF $(\mathrm{p}<0.05 / \mathrm{p}<0.01)$ was significantly higher than in control subjects, while the per cent of eosinophils in sarcoidosis was not increased. The absolute number of eosinophils was increased in patients with BOOP compared with healthy volunteers, but the difference was not significant (table 1). The percentage of lymphocytes was significantly higher in patients with BOOP $(p<0.01)$ and sarcoidosis $(p<0.05)$ than in healthy subjects. The percentage of neutrophils in the EP $(\mathrm{p}<0.05)$, BOOP $(\mathrm{p}<0.05)$, and IPF $(\mathrm{p}<0.01)$ patients was significantly higher than in controls.

Interleukin 5, 3 and granulocyte-macrophage colonystimulating factor levels in bronchoalveolar lavage fluid

Interestingly, IL-5 was detected only in patients with EP. Furthermore, follow-up lavages were performed in three of the nine patients with EP after treatment with corticosteroids, IL-5 was not detected in any follow-up lavage (data not shown). Although the number of eosinophils was high in patients with BOOP and IPF, IL-5 was not detected in any patient with these diseases (fig. 1). Furthermore, IL-5 in BALF was below the detection limit in healthy subjects and patients with sarcoidosis. IL-3 was detected in two of the six patients with EP and one of the 13 with BOOP (fig. 2a) while GM-CSF was detected in four of the nine patients with EP and three of the 10 with both BOOP and IPF (fig. 2b). IL-3 and GM-CSF were not detected in BALF of all healthy subjects. There were no significant differences in cytokine (IL-5, IL-3, GM-CSF) levels of BALF between smokers and nonsmokers in each disease.

Relationship between eosinophilia and granulocyte-macrophage colony-stimulating factor in bronchoalveolar lavage fluid

To evaluate the role of GM-CSF in EP, BOOP and IPF, patients were divided into two groups depending on the level of GM-CSF in BALF (below or above the detection limit; $\left.3.9 \mathrm{pg} \cdot \mathrm{mL}^{-1}\right)$. In patients with BOOP and IPF, the

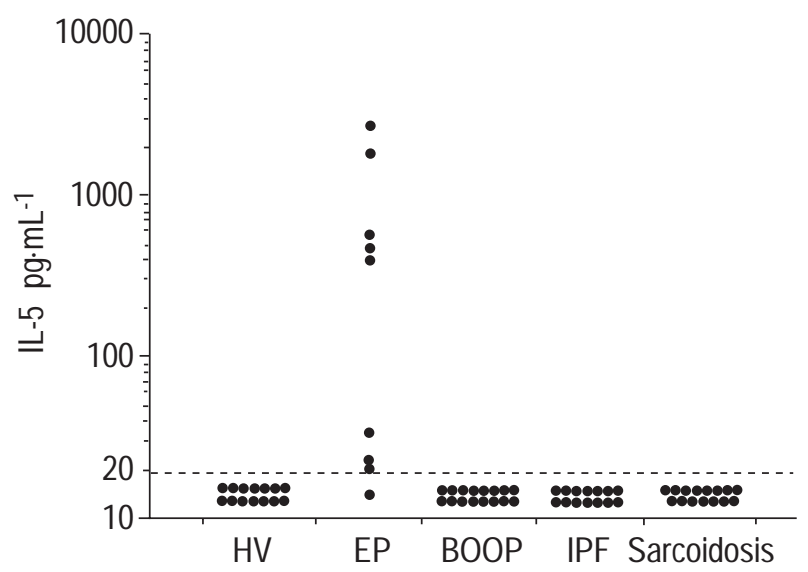

Fig. 1. - Concentrations of interleukin (IL)-5 in bronchoalveolar lavage fluid obtained from patients with eosinophilic pneumonia (EP), bronchiolitis obliterans organizing pneumonia (BOOP), idiopathic pulmonary fibrosis (IPF), sarcoidosis and healthy volunteers (HV), measured by enzyme-linked immunosorbent assay. The detection limit of IL-5 is represented as a horizontal dotted line.

absolute number of eosinophils in BALF was significantly higher in GM-CSF-detectable groups compared with GMCSF-undetectable groups $(\mathrm{p}<0.05)$. In patients with EP, however, the absolute number of eosinophils was not significantly different between the two groups (fig. 3). Because GM-CSF is also a growth and differentiation factor of neutrophils, the absolute numbers of neutrophils in BALF of these patients were also compared. There was no relationship between lung neutrophilia and GM-CSF levels in BALF (fig. 3b).

Eosinophil cationic protein concentration in bronchoalveolar lavage fluid

The concentration of ECP in BALF was evaluated in patients with lung eosinophilia. ECP was detected in all patients with EP, one of the 12 patients with BOOP and five of the 14 with IPF (fig. 4a). Furthermore, there was a significant correlation between ECP concentration and percentage of eosinophils $(\mathrm{r}=0.533, \mathrm{p}<0.01)$ (fig. $4 \mathrm{~b})$ or absolute eosinophil numbers $(\mathrm{r}=0.392, \mathrm{p}<0.01)$ in BALF.

\section{Discussion}

The major findings of the present study were that IL-5 and GM-CSF could be involved in the recruitment of eosinophils into the lung in patients with certain ILDs.

Table 1. - Characteristics of bronchoalveolar lavage fluid cells in interstitial lung disease

\begin{tabular}{|c|c|c|c|c|c|c|c|}
\hline & $\begin{array}{c}\text { Volume } \\
\text { recovered \% }\end{array}$ & $\begin{array}{l}\text { Total cells } \\
10^{5} \cdot \mathrm{mL}^{-1}\end{array}$ & $\begin{array}{c}\text { Macrophages } \\
\%\end{array}$ & $\begin{array}{c}\text { Lymphocytes } \\
\%\end{array}$ & $\begin{array}{l}\text { Neutrophils } \\
\% \%\end{array}$ & $\begin{array}{c}\text { Eosinophils } \\
\% \%\end{array}$ & $\begin{array}{c}\text { Eosinophils } \\
10^{3} \cdot \mathrm{mL}^{-1}\end{array}$ \\
\hline $\mathrm{HV}$ & $64.5 \pm 9.7$ & $1.5 \pm 0.7$ & $87.3 \pm 6.9$ & $10.1 \pm 6.0$ & $1.7 \pm 3.6$ & $0.9 \pm 2.0$ & $1.6 \pm 3.9$ \\
\hline EP & $42.9 \pm 23.6^{*}$ & $8.0 \pm 6.6^{* *}$ & $23.4 \pm 14.0 * *$ & $19.0 \pm 13.0$ & $9.1 \pm 12.5^{*}$ & $47.6 \pm 23.4 * *$ & $460.9 \pm 573.6^{* *}$ \\
\hline BOOP & $44.5 \pm 14.9 * *$ & $10.4 \pm 19.7$ & $50.8 \pm 30.5^{* *}$ & $29.5 \pm 24.0 *$ & $14.7 \pm 27.7^{*}$ & $1.3 \pm 1.7$ & $7.1 \pm 11.0$ \\
\hline IPF & $41.1 \pm 14.9 * *$ & $4.4 \pm 2.9 * *$ & $66.7 \pm 22.6^{* *}$ & $17.9 \pm 18.1$ & $10.3 \pm 11.4^{* *}$ & $5.0 \pm 7.3^{*}$ & $27.0 \pm 60.0 * *$ \\
\hline Sar & $58.4 \pm 11.8$ & $3.1 \pm 2.2 *$ & $58.2 \pm 22.7 * *$ & $39.8 \pm 21.6^{* *}$ & $1.6 \pm 2.2$ & $0.5 \pm 0.9 * *$ & $4.4 \pm 12.3$ \\
\hline
\end{tabular}

Data are presented as mean $\pm \mathrm{SD} .{ }^{*}: \mathrm{p}<0.05 ; * *: \mathrm{p}<0.01$; both compared with healthy volunteer subjects. HV: healthy volunteer subjects $(n=14)$; EP: eosinophilic pneumonia $(n=9)$; BOOP: bronchiolitis obliterans organizing pneumonia $(n=16)$; IPF: idiopathic pulmonary fibrosis $(n=14)$; Sar: sarcoidosis $(n=17)$. 

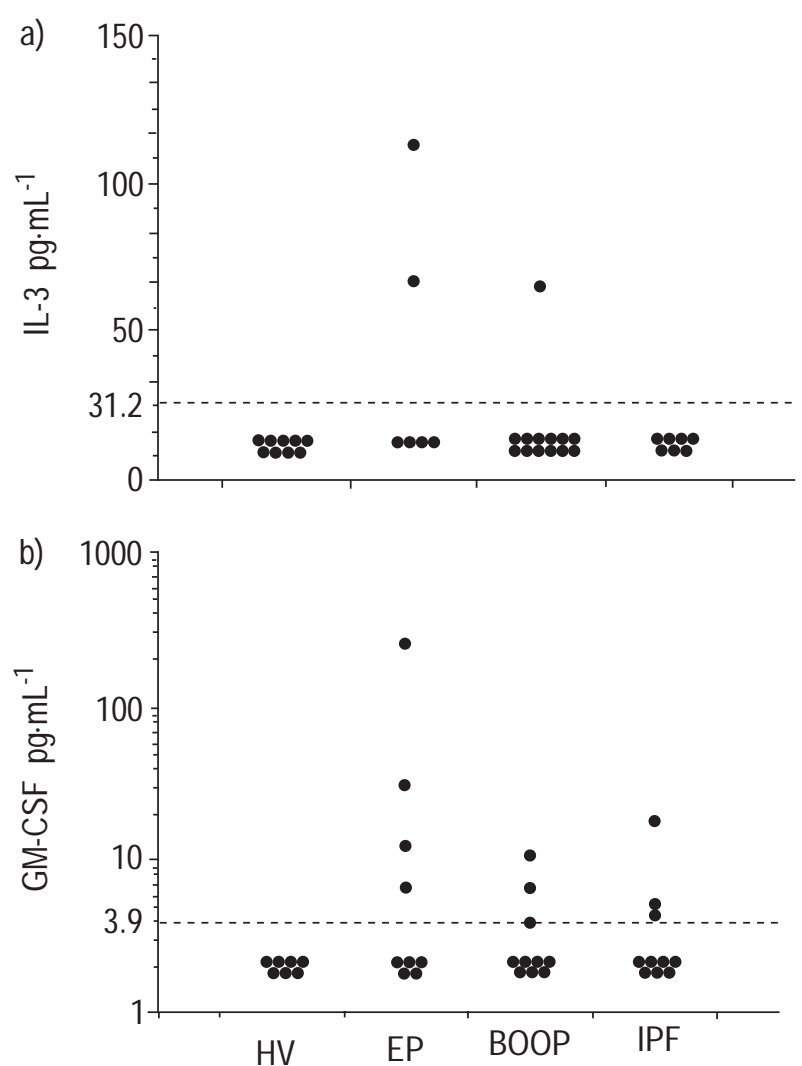

Fig. 2. - Concentrations of a) interleukin (IL)-3 and b) granulocytemacrophage colony-stimulating factor (GM-CSF) in bronchoalveolar lavage fluid obtained from patients with eosinophilic pneumonia (EP), bronchiolitis obliterans organizing pneumonia (BOOP), idiopathic pulmonary fibrosis (IPF) and healthy volunteers (HV), measured by enzyme-linked immunosorbent assay. The detection limits of each cytokine are represented as horizontal dotted lines.

ECP is a cytotoxic component of eosinophil granules [21-23]. In this study, a correlation between increased ECP levels and eosinophilia in BALF was demonstrated. It has previously been reported that ECP levels in BALF were correlated with the eosinophil numbers in BALF of patients with EP and IPF [14, 24, 25]. These findings appear to reflect local secretion and/or leakage of ECP by activated eosinophils.

IL-5, IL-3 and GM-CSF are proliferation, differentiation and activation factors of eosinophils [3, 26, 27]. IL-5 especially promotes the terminal differentiation of eosinophil progenitors in human bone marrow [26, 27] and is a selective activator of mature eosinophils in humans [4, 5]. As previously reported by OCHIAI et al. [28], the BALF of two EP patients in the present study also increased the survival rate of eosinophils in vitro, and that effect on eosinophils was completely blocked by addition of antiIL-5 monoclonal antibody (data not shown). Furthermore, previous studies have demonstrated that elevated IL-5 was detected in BALF and serum from patients with symptomatic, but not asymptomatic asthma [29, 30]. These studies suggested that IL-5 may become detectable as asthma progresses to a symptomatic state. However, there have been only a few detailed reports demonstrating that high IL-5 levels were detected in BALF from ILD $[16,31]$. In the present study, IL-5 was detected only in BALF of patients with EP. This finding is inconsistent a)

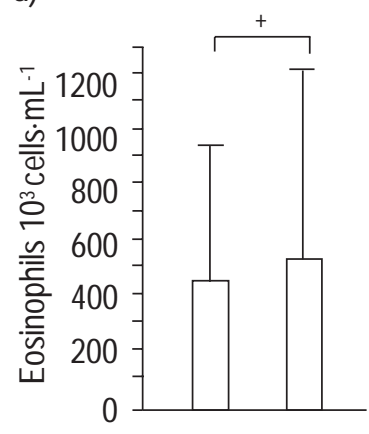

c)

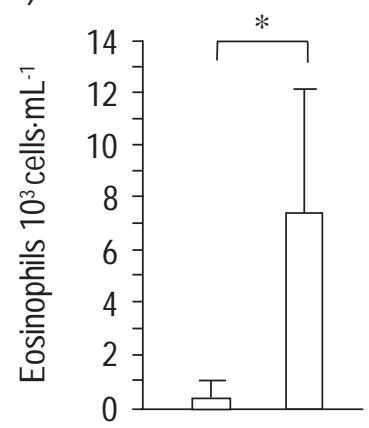

e)

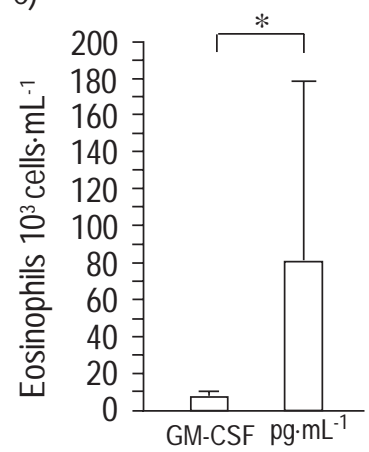

b)

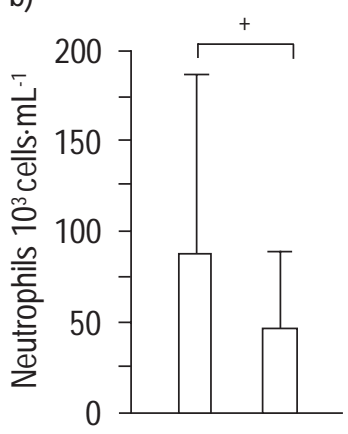

d)

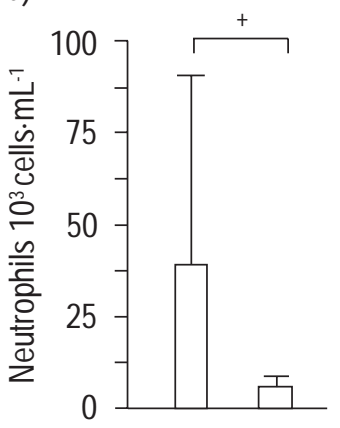

f)

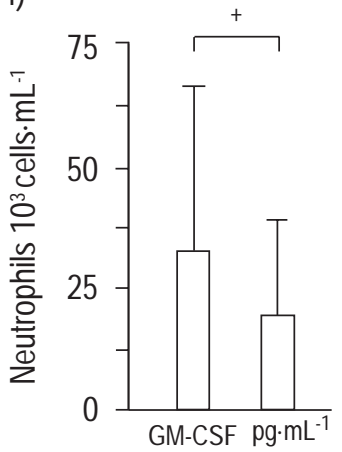

Fig. 3. - Absolute numbers of a, c, e) eosinophils; and b, d, f) neutrophils in the bronchoalveolar lavage fluid of patients with: $a, b$ ) eosinophilic pneumonia c, d) bronchiolitis obliterans organizing pneumonia, and e, f) idiopathic pulmonary fibrosis. Patients from each group were divided into two subgroups based on the level of granulocyte-macrophage colony-stimulating factor (GM-CSF) (below or above the detection limit $\left(3.9 \mathrm{pg} \cdot \mathrm{mL}^{-1}\right)$. Data are presented as mean $\pm \mathrm{SD}$. + : nonsignificant; $*$ : $\mathrm{p}<0.05$.

with those reported earlier by WALKER et al. [16] who demonstrated elevated IL-5 in both EP and IPF. In their study, IL-5 levels in EP were only a few times higher than those in IPF, whereas in this present study, extremely high levels of IL-5 were detected in EP compared with IPF. This discrepancy may result from the use of a different methodology. WALKER et al. [16] used concentrated BALF in proliferation assays using a cytokinespecific cell line, which may reflect cytokine activity, while protein concentration was measured with the ELISA method in this study. Furthermore, both acute and chronic EP were included in patients with EP which were examined in the present study. These may explain the finding that IL-5 concentration in BALF did not 

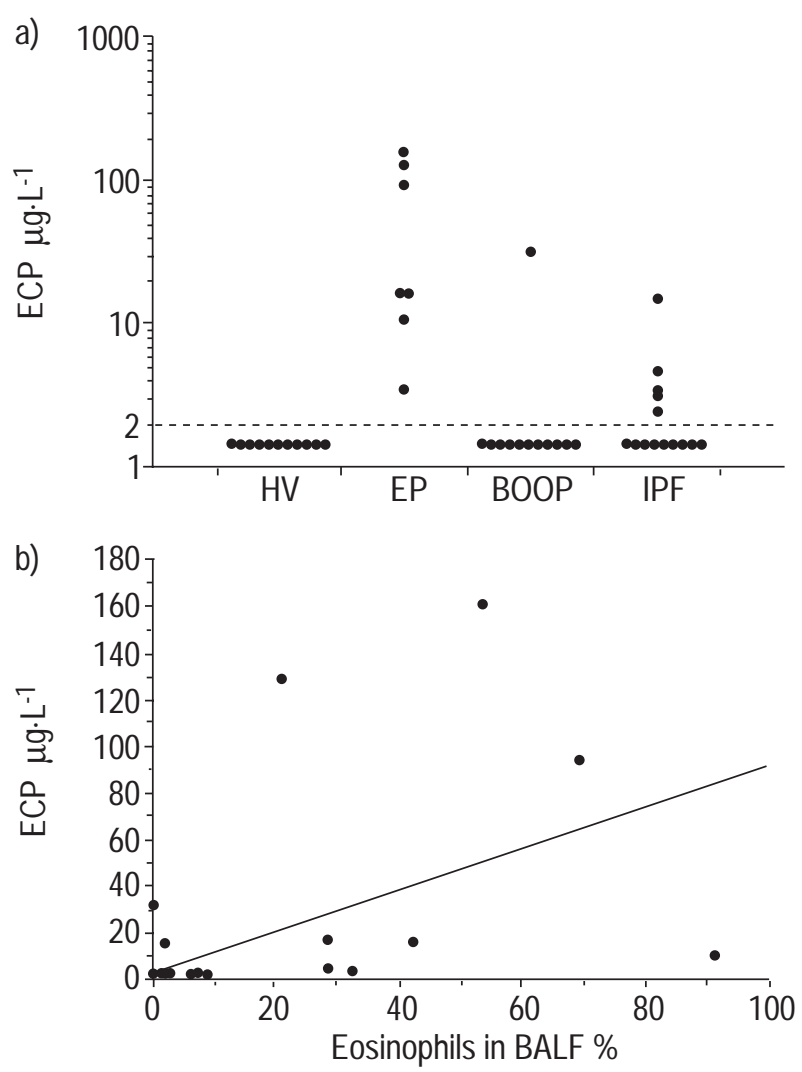

Fig. 4. - a) Concentrations of eosinophil cationic protein (ECP) in the bronchoalveolar lavage fluid (BALF) of patients with eosinophilic pneumonia (EP), bronchiolitis obliterans organizing pneumonia (BOOP), idiopathic pulmonary fibrosis (IPF) and healthy volunteers (HV), measured by radioimmunoassay. b) Note the positive correlation between the percentage of eosinophils and ECP concentration in BALF from all patients $(\mathrm{r}=0.533, \mathrm{p}<0.01)$.

correlate with the percentage and number of eosinophils in BALF of EP patients (data not shown). Nevertheless, these observations indicate that IL-5 may play an important role in pulmonary eosinophilia in patients with EP. Inhibition of IL-5 production may be a potential specific treatment for this disease.

IL-3 and GM-CSF have pronounced effects on eosinophils, but their functions are not selective to eosinophils [29]. In this study, IL-3 was undetectable in BALF in the majority of patients (23 of the 26), suggesting that it is unlikely to be involved in the pathogenesis of ILD. On the other hand, detectable levels of GM-CSF were present in BALF in 4 of the $9 \mathrm{EP}$ patients $(44.4 \%)$ and in 3 of the 10 patients with both BOOP and IPF (30\%). Although GM-CSF was detected in a low number of patients, eosinophil numbers in BALF were significantly higher in GM-CSF-detectable groups than GM-CSF-undetectable groups of BOOP and IPF patients (fig. 3a). These findings suggest that GM-CSF could in part contribute to lung eosinophilia in patients with BOOP and IPF, and also suggest the possibility that different eosinophil growth factors might cause lung eosinophilia in various eosinophilic lung diseases. The authors have previously reported that different subpopulations of T cells, CD4+ human leukocyte antigen (HLA)-DR+ cells and CD8+HLA-DR+ cells, in BALF were increased in EP and BOOP respectively [32].
To conclude it has been demonstrated that interleukin 5 may play an important role in the pathogenesis of eosinophil infiltration in the lung in patients with eosinophilic pneumonia. Further studies are necessary to elucidate the cytokine-producing cells and the stimulatory mechanisms of cytokine production in different eosinophilic lung diseases.

\begin{abstract}
Acknowledgements. The authors would like to thank K. Takatsu and Y. Kikuchi for technical advice regarding the interleukin 5 enzyme-linked immunosorbent assay, and A. Yokoyama for technical assistance.
\end{abstract}

\section{References}

1. Clark SC, Kamen R. The human hematopoietic colonystimulating factors. Science 1987; 236: 1229-1237.

2. Rovatti E, Franchi A, Richeldi L, Saltini C. Lymphokines. In: Crystal RG, West JB, Weibel ER, Barnes PJ, eds. The Lung. 2nd ed. Philadelphia, Lippincott-Raven Publishers, 1997; pp. 187-199.

3. Clutterbuck EJ, Sanderson CJ. Regulation of human eosinophil precursor production by cytokines: a comparison of recombinant human interleukin-1(rhIL-1), rhIL-3, rhIL-5, rhIL-6, and rh-granulocyte-macrophage colony-stimulating factor. Blood 1990; 75: 1774-1779.

4. Lopez AF, Sanderson CJ, Gamble JR, Campbell HD, Young IG, Vadas MA. Recombinant human interleukin 5 is a selective activator of human eosinophil function. $J$ Exp Med 1988; 167: 219-224.

5. Takatsu K, Tominaga A, Harada N, et al. T cell replacing factor (TRF)/ interleukin-5 (IL-5): molecular and functional properties. Immunol Rev 1988; 102: 107-135.

6. Tominaga A, Takaki S, Koyama N, et al. Transgenic mice expressing a B cell growth and differentiation factor gene (interleukin 5) develop eosinophilia and autoantibody production. $J$ Exp Med 1991; 173: 429-437.

7. Wang JM, Rambaldi A, Biondi A, Chen ZG, Sanderson $\mathrm{CJ}$, Mantovani A. Recombinant human interleukin 5 is a selective eosinophil chemoattractant. Eur J Immunol 1989; 19: 701-705.

8. Okudaira H, Nogami M, Matsuzaki G, et al. T-celldependent accumulation of eosinophils in the lung and its inhibition by monoclonal anti-interleukin-5. Int Arch Allergy Appl Immunol 1991; 94: 171-173.

9. Kopf M, Brombacher F, Hodgkin PD, et al. IL-5-deficient mice have a developmental defect in CD5+ B-1 cells and lack eosinophilia but have normal antibody and cytotoxic T cell responses. Immunity 1996; 4: 13-24.

10. Yoshida T, Ikuta K, Sugaya H, et al. Defective B-1 development and impaired immunity against Angiostrongylus cantonensis in IL-5Ra-deficient mice. Immunity 1996; 4: 483-494.

11. Silberstein DS, David JR. The regulation of human eosinophil function by cytokines. Immunology Today 1987; 8: 380-385.

12. Rothenberg ME, Owen WF Jr, Silberstein DS, et al. Human eosinophils have prolonged survival, enhanced functional properties, and become hypodense when exposed to human interleukin 3. J Clin Invest 1988; 81: 1986-1992. 
13. Hällgren R, Bjermer L, Lundgren R, Venge P. The eosinophil component of the alveolitis in idiopathic pulmonary fibrosis: signs of eosinophil activation in the lung are related to impaired lung function. Am Rev Respir Dis 1989; 139: 373-377.

14. Shijubo N, Shigehara K, Hirasawa M, Inuzuka M, Abe S. Eosinophilic cationic protein in chronic eosinophilic pneumonia and eosinophilic granuloma. Chest 1994; 106: 1481-1486.

15. Allen JN, Davis WB, Pacht ER. Diagnostic significant of increased bronchoalveolar lavage fluid eosinophils. $\mathrm{Am}$ Rev Respir Dis 1990; 142: 642-647.

16. Walker C, Bauer W, Braun RK, et al. Activated T cells and cytokines in bronchoalveolar lavages from patients with various lung disease associated with eosinophilia. Am J Respir Crit Care Med 1994; 150: 1038-1048.

17. Albera C, Ghio P. Eosinophils in eosinophilic pneumonia. Eur Respir J 1996; 9: 2437-2439.

18. Epler GR, Colby TV, McLoud TC, et al. Bronchiolitis obliterans organizing pneumonia. $N$ Engl J Med 1985; 312: $152-158$.

19. Mukae H, Kadota J, Kohno S, et al. Increased in activated $\mathrm{CD} 8+$ cells in bronchoalveolar lavage fluid in patients with diffuse panbronchiolitis. Am J Respir Crit Care Med 1995; 152: 613-618.

20. Kadota J, Matsubara Y, Ishimatsu Y, et al. Significance of IL-1b and IL-1 receptor antagonist (IL-1Ra) in bronchoalveolar lavage fluid (BALF) in patients with diffuse panbronchiolitis (DPB). Clin Exp Immunol 1996; 103: 461-466.

21. Ackerman SJ, Loegering DA, Venge P, et al. Distinctive cationic proteins of the human eosinophil granule: major basic protein, eosinophil cationic protein and eosinophilderived neurotoxin. J Immunol 1983; 131: 2977-2982.

22. Young JDE, Peterson CGB, Venge P, Cohn ZA. Mechanism of membrane damage mediated by human eosinophil cationic protein. Nature 1986; 321: 613-616.

23. Motojima S, Frigas E, Loegering DA, Gliech GJ. Toxicity of eosinophil cationic proteins for guinea pig tracheal epithelium in vitro. Am Rev Respir Dis 1989; 139: 801805.

24. Fujimoto K, Kubo K, Yamaguchi S, Honda T, Matsuzawa Y. Eosinophil activation in patients with pulmonary fibrosis. Chest 1995; 108: 48-54.

25. Boomars KA, van Velzen-Blad H, Mulder PGH, Koenderman L, Lammers JWJ, van den Bosch JMM. Eosinophil cationic protein and immunoglobulin levels in bronchoalveolar lavage fluid obtained from patients with chronic eosinophilic pneumonia. Eur Respir J 1996; 9: 2488-2493.

26. Sonoda Y, Arai N, Ogawa M. Human regulation of eosinophilopoiesis in vitro: analysis of the targets of interleukin-3, granulocyte/macrophage colony-stimulating factor (GM-CSF), and interleukin-5. Leukemia 1989; 2: 14-18.

27. Sanderson CJ. Interleukin-5, eosinophils and disease. Blood 1992; 79: 3101-3109.

28. Ochiai K, Kagami M, Matsumura R, Tomioka H. IL-5 but not interferon-gamma (IFN-r) inhibits eosinophil apoptosis by up-regulation of bcl-2 expression. Clin Exp Immunol 1997; 107: 198-204.

29. Broide DH, Lotz M, Cuomo AJ, Coburn DA, Federman EC, Wasserman SI. Cytokines in symptomatic asthma airways. J Allergy Clin Immunol 1992; 89: 958-967.

30. Sur S, Gleich GJ, Swanson MC, Bartemes KR, Broide $\mathrm{DH}$. Eosinophilic inflammation is associated with elevation of interleukin-5 in the airways of patients with spontaneous symptomatic asthma. $J$ Allergy Clin Immunol 1995; 96: 661-668.

31. Allen JN, Liao Z, Wewers MD, Altenberger EA, Moore $\mathrm{SA}$, Allen ED. Detection of IL-5 and IL-1 receptor antagonist in bronchoalveolar lavage fluid in acute eosinophilic pneumonia. J Allergy Clin Immunol 1996; 97: 1366-1374.

32. Mukae H, Kadota J, Kohno S, Matsukura S, Hara K. Increase of activated T-cells in BAL fluid of Japanese patients with bronchiolitis obliterans organizing pneumonia and chronic eosinophilic pneumonia. Chest 1995; 108: $123-128$. 